Article

\title{
Measuring Progress toward Urban Sustainability: Do Global Measures Work for Arctic Cities?
}

\author{
Matthew Berman ${ }^{1}\left(\mathbb{D}\right.$ and Robert W. Orttung ${ }^{2, *(1)}$ \\ 1 Institute of Social and Economic Research, University of Alaska Anchorage, Anchorage, AK 99508, USA; \\ matthew.berman@alaska.edu \\ 2 Sustainable GW and Institute for European, Russian and Eurasian Studies, George Washington University, \\ Washington, DC 20052, USA \\ * Correspondence: rorttung@gwu.edu
}

Received: 30 March 2020; Accepted: 28 April 2020; Published: 3 May 2020

check for updates

\begin{abstract}
The International Organization for Standardization recently responded to a growing global interest in cities by developing an index for measuring urban sustainability (ISO 37120). We address how well this standard applies to Arctic cities, and potential modifications that might improve its performance. After briefly discussing the goals of sustainability indicators, we examine the extent to which Arctic cities' remote location, cold and changing climate, and thin, largely resource-based economies may create different sustainability challenges. We then critically examine the content of ISO 37120 and the context in which it was created. We place the index within a broader discussion of urban sustainability indicators and examine the extent to which it really addresses sustainability. We then analyze how well the ISO 37120 accounts for the characteristic features of Arctic cities that produce unique sustainability challenges. Our findings show that only half of ISO $37120^{\prime} \mathrm{s}$ 128 indicators actually measure future-oriented concerns. We suggest that, while the ISO 37120 may be a useful starting point in quantifying Arctic urban sustainability, the index should only be used as a foundation for a more in-depth analysis. To better represent Arctic cities, the ISO 37120 would need to include indicators that situate cities within their regional contexts, addressing both remoteness and the underlying basis of the Arctic city economy. The index should also measure the role of Indigenous populations, and chart the extent to which cities are working to increase levels of sustainability.
\end{abstract}

Keywords: Arctic; ISO 37120; indicators; urban

\section{Introduction}

The Arctic is becoming increasingly urbanized. More than two-thirds of the population lives in larger settlements [1], and the growing concentration of people is likely to continue [2-4]. Despite the trend toward urbanization, relatively little is known about Arctic cities. The Arctic Human Development Report identified "Arctic settlements, cities, and communities" as one of the main gaps in knowledge of the region [5]. One of the most important issues facing Arctic regions is the perceived need to transition from a "boom-bust" cycle, based on resource extraction, to a more diverse and sustainable economy [6-8]. The sustainability challenge is particularly important for Arctic cities, as they will continue to absorb an even greater share of the Arctic population [9].

In order to evaluate progress towards the sustainability of Arctic cities, one has to define sustainability in measurable terms. Responding to a growing interest in measuring urban sustainability globally [10-13], the International Organization for Standardization (ISO) defined a comprehensive set of indicators for measuring urban sustainability. The ISO 37120 standard, Sustainable Cities and Communities-Indicators for City Services and Quality of Life, formally adopted in 2014 and revised in 2018, now includes 128 indicators over 19 domains (dimensions) of sustainability [14,15]. Despite the 
enormous diversity in cities, ranging from urban areas dealing with extensive poverty and unmet needs to those that consume enormous resources in wasteful and polluting ways, the ISO standard is intended to apply to cities globally [16]. Is it appropriate for Arctic cities, or do they need their own set of measures?

Our research question is part of a broader literature that addresses the issue of whether one set of standards applies to all cities on the planet, or if there are groups of cities that are sufficiently different from the rest that they deserve special consideration. From one perspective, it is possible to argue that each city is unique, and one must understand the local context in order to measure the level of sustainability with any accuracy. Cities differ across so many dimensions-wealth, history, culture, governance- that it is impossible to come up with a one size fits all solution to sustainability [17]. This rejection of universals might be described as "sustainability nominalism" [18]. On the other hand, cities are all basically alike, in that they have the legitimacy and authority to solve problems within their borders [19]. Seeking the proper balance between uniqueness and generality, the authors of the U.S. National Academy of Sciences' report on urban sustainability concluded that "Urban leaders and planners should look to cities with similar economic, environmental, social, and political contexts to understand and adapt local and regional sustainability strategies that have proven to provide measurable impact [20]". While this broader question has been discussed in the literature, this article will be one of the first to examine it in the context of ISO 37120 [21].

To answer our research question-Is ISO 37120 useful in measuring the sustainability of Arctic cities? - we first discuss important features of Arctic cities, focusing on characteristics that set them apart from cities elsewhere and potentially require different sustainability measures. We describe how Arctic cities are embedded in a regional system that is itself connected to larger-scale global systems, and use that context to identify criteria to evaluate how well the ISO standard works to measure Arctic urban sustainability. Next, we critically examine the content of ISO 37120 and the context in which it was created. We place ISO 37120 into the broader discussion of urban sustainability indicators and examine the extent to which it really measures sustainability. Next, we analyze the extent to which ISO 37120 is able to account for the unique features of Arctic cities that produce different sustainability challenges, while also measuring aspects of performance relevant to all cities. The concluding section discusses specific modifications to the ISO standard that might make it more relevant to Arctic cities, and considers what additional changes might make a revised index more useful for local governments as they develop and implement plans to achieve sustainability goals.

\section{Arctic Cities in Context}

Although Arctic cities share many characteristics and problems with cities worldwide, they differ in important respects [22,23]. Often, these differences are a matter of degree; however, Arctic cities as a group exhibit patterns of similarity that set them apart from global urban norms (Figure 1). Arctic cities tend to be smaller. The largest Arctic city-Arkhangelsk, Russia-contains about 350,000 inhabitants, followed by three others: Yakutsk and Murmansk-also in Russia, and Anchorage, Alaska, with populations around 300,000. Only about a dozen Arctic cities have more than 100,000 residents.

Arctic cities share certain characteristics because of their location. Being in higher latitudes, they experience profound swings in seasonal daylight hours, and of course, are typically cold. The lack of daylight in winter creates a challenge for energy sustainability because it curtails the possibility of using solar energy at the time of year when demand for light and space heating is greatest. Conversely, the higher energy needs in winter make energy efficiency a more salient concern. Cold soil temperatures also mean permafrost. Maintaining the integrity of permafrost and adapting infrastructure to permafrost thaw is a major sustainability challenge for many Arctic cities [24], a challenge that cities elsewhere avoid entirely. Arctic cities, on the other hand, do not avoid issues such as increased floods and droughts, and encroachment of seas associated with a warming climate; in fact, the effects of climate change are magnified in the Arctic [25]. 


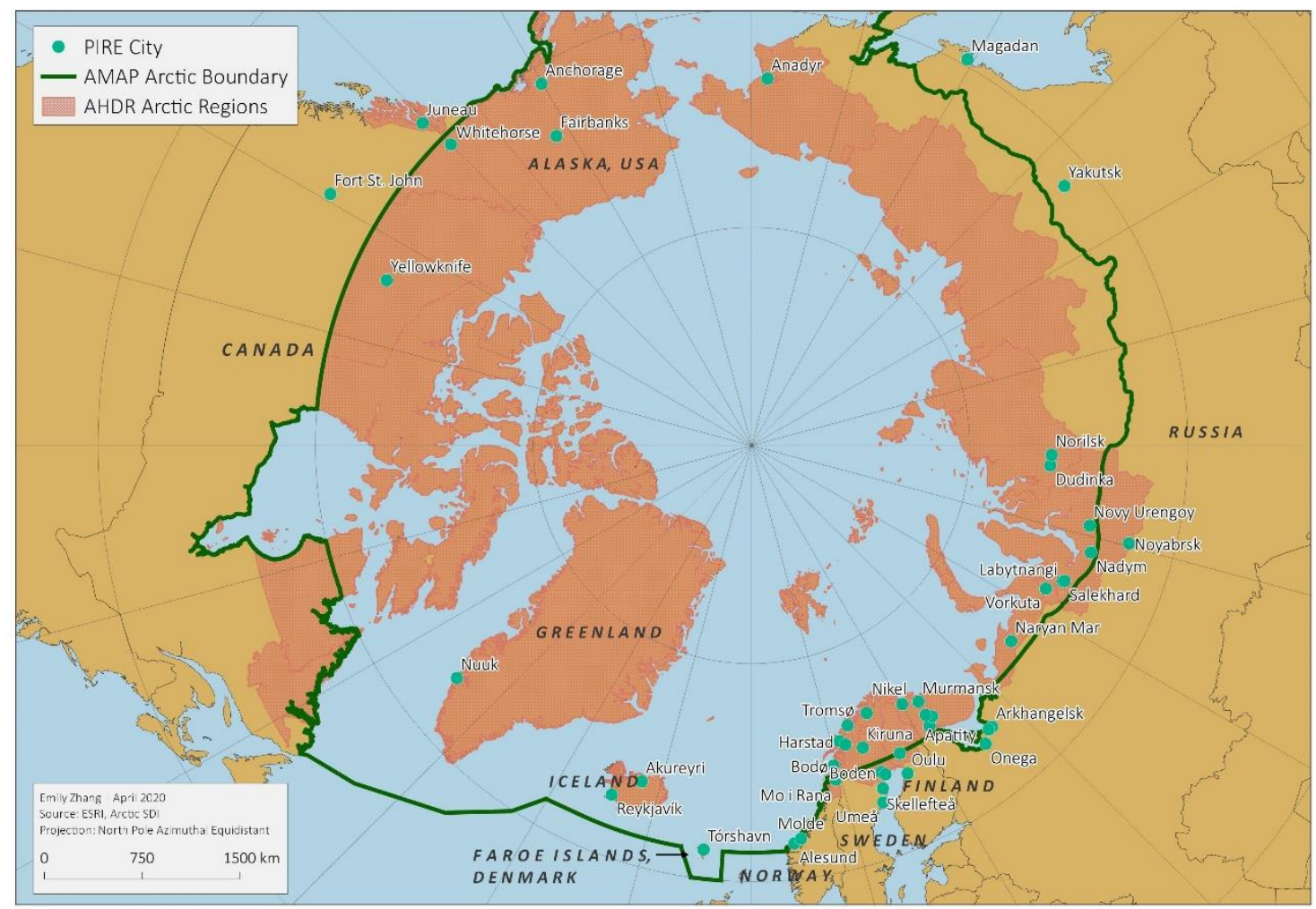

Figure 1. Arctic cities included in our analysis.

Perhaps the most distinguishing geographic feature of Arctic cities is their relative remoteness. Arctic regions are located far from markets and centers of commerce [26]. Geographic isolation separates producers from consumers, which increases transportation costs. Higher transport expenditures increase the cost of business, reducing economic opportunities while raising the cost of living. Only one Arctic region, Iceland, is a nation-state. With that exception, all Arctic cities are geographically remote from centers of political power. Even in the age of globalization and the internet, the Arctic remains culturally distant, often portrayed as the exotic "other" in popular culture $[27,28]$.

Remoteness of Arctic regions is internal and external [29,30]. A thin regional surface transportation network connects Arctic cities to sparsely populated hinterlands, requiring reliance on air and water transportation [31]. Transportation routes emphasize north-south connections: Arctic cities are rarely connected to each other. Reykjavik and Anchorage represent exceptions to this rule, and serve as global air transport hubs. These exceptions-Reykjavik serving as a hub for passenger traffic between North America and Europe; Anchorage serving as a cargo hub for shipping between North America and Asia-only emphasize the tyranny of geography in shaping opportunities for Arctic cities.

Geographic factors are not the only characteristics that distinguish Arctic cities from their more southerly counterparts. The economic forces that shape their dynamics are qualitatively different from those of most cities outside the Arctic. Cities have been described as engines of growth and prosperity, taking advantage of agglomeration economies that generate internally fueled growth [32-34]. Their dynamism and relative prosperity attracts migrants from the surrounding hinterlands, where livelihoods are often agricultural [35]. Arctic cities do indeed attract migrants from their hinterlands, but the infeasibility of agriculture keeps these areas sparsely populated. Instead, most population movements in the Arctic consists of migration between the Arctic and other regions [36].

In sharp contrast to the model of self-fueled urban growth, Arctic cities have long been viewed as economically dependent on their regional hinterlands [37]. Arctic cities are firmly embedded within the regional Arctic system, serving as administrative, financial, and logistic centers for the 
surrounding territory (Figure 2). The regional economy that supports the Arctic city is typically thin. Huskey et al. [26] described three pillars of the Arctic economy: Natural resource extraction, national government administration, and traditional economies of the rural Indigenous population. Natural resource extraction is driven by global markets, over which the Arctic city has no control [38]. In some areas, tourism represents an important part of the private economy, with the Arctic city again providing logistics support for travel to sites in the region. Arctic tourism-predominantly ecotourism and cultural tourism - could be viewed as an extension of natural resource production, also driven by global market forces outside the city's control [39-41]. National geopolitical interests drive both civilian and military expenditures for administration over lands, resources, and support for residents in the Arctic. In all cases, the regional system, which is itself driven by external forces, shapes the dynamics of the Arctic city, not the reverse.

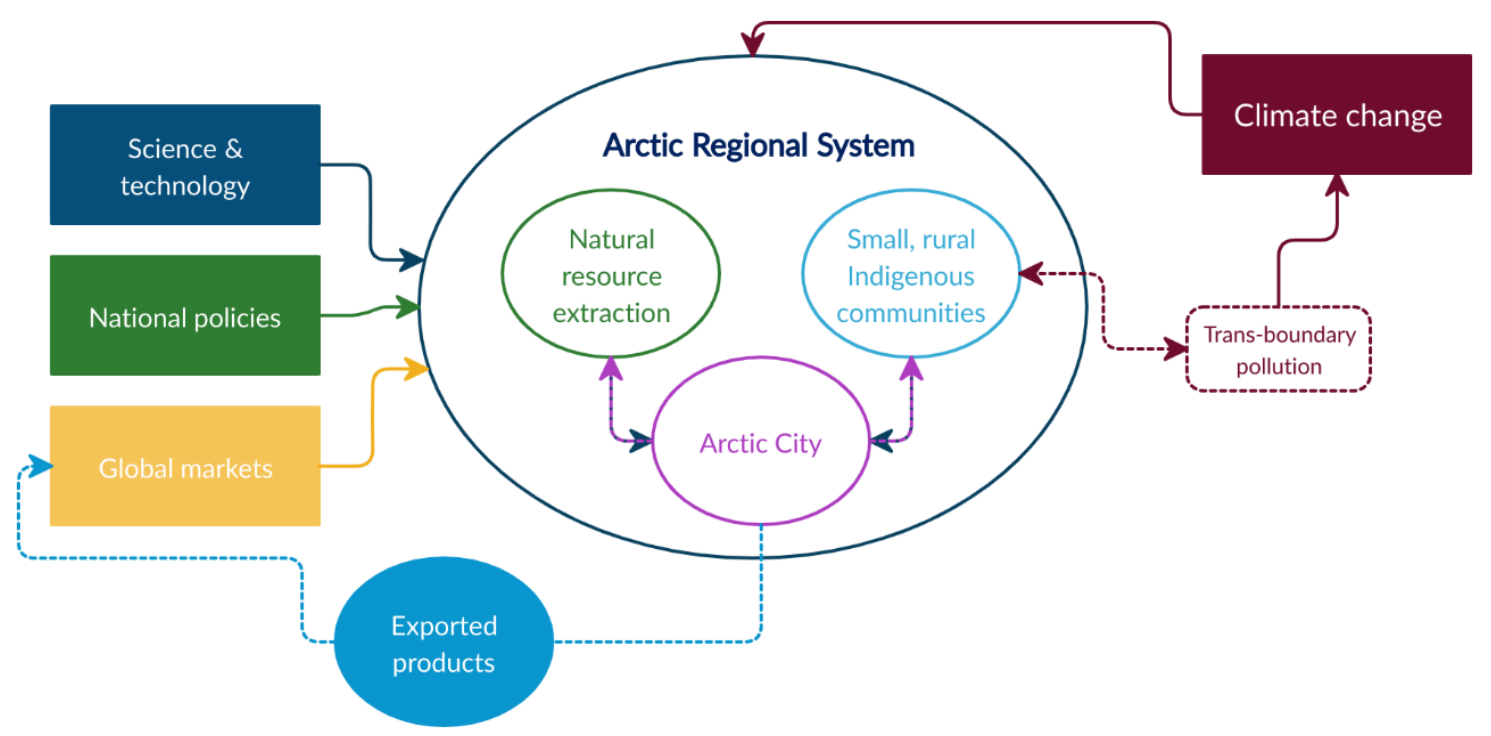

Figure 2. The Arctic Regional System in Context. Global markets, national policies, scientific advances, and climate change are external drivers that affect the Arctic regional system. The Arctic region also exports products such as oil and gas that may affect global markets.

Finally, Arctic cities are relatively recent arrivals in the Arctic region and overall. They can grow and decline rapidly as their regional economies experience waves of expansion and contraction [42,43]. Because of their relatively young age, urban infrastructure is often limited and inadequate to serve the population. Unstable economies suggest that investments to build infrastructure that carries high maintenance costs could be unwise, despite the perceived need. The highly mobile population means that the Arctic city is often contending with assimilating a large cadre of immigrants from outside as well as within the Arctic [44], who may require additional services.

All the characteristics of Arctic cities described above create additional challenges for urban sustainability that cities outside the Arctic typically do not face. Indicators for urban sustainability designed for global cities may or may not be flexible enough to accommodate large differences among cities. Table 1 summarizes the unique features of Arctic cities enumerated above, along with associated criteria for evaluating the suitability of an urban sustainability index such as ISO 37120 for Arctic cities. Table 1 addresses only the potential differences between characteristics of Arctic and non-Arctic cities that the index needs to accommodate. Arctic cities also face many of the same sustainability challenges and opportunities faced by urban centers globally. Accordingly, we recognize and expect that a large set of indicators developed for cities outside Arctic regions will also apply to Arctic cities. 
Table 1. Characteristic features of arctic cities and associated criteria for evaluating suitability of sustainability indicators.

\begin{tabular}{|c|c|}
\hline Characteristic Feature of Arctic City & Criteria for Suitable Indicators \\
\hline Economic dependence on natural resources & $\begin{array}{l}\text { Measure percentage of employment and income not } \\
\text { tied to nonrenewable resource extraction }\end{array}$ \\
\hline $\begin{array}{l}\text { Sustainable urban economy depends on a sustainable } \\
\text { regional economy }\end{array}$ & $\begin{array}{l}\text { Maintain regional ecosystem integrity, cultural } \\
\text { integrity of regional Indigenous population }\end{array}$ \\
\hline Regional economies potentially unstable & $\begin{array}{l}\text { Measure adaptive capacity rather than } \\
\text { current outcomes }\end{array}$ \\
\hline Challenges of climate and latitude & Energy indicators should prioritize efficiency \\
\hline Permafrost may be present & Appropriate construction standards \\
\hline $\begin{array}{l}\text { Typically smaller cities with limited } \\
\text { administrative capacity }\end{array}$ & $\begin{array}{l}\text { Avoid complex measures and administratively } \\
\text { costly programs }\end{array}$ \\
\hline Internal as well as external remoteness & $\begin{array}{c}\text { Measure air connectivity and internet access rather } \\
\text { than road connections }\end{array}$ \\
\hline Relatively short lifespan & Emphasize investment over capacity \\
\hline Migrant population & Programs to assist immigrants \\
\hline
\end{tabular}

Before concluding this section outlining the differences between Arctic cities and non-Arctic cities, we want to stress that despite their many similarities, Arctic cities are themselves quite diverse, and differ from each other in many ways. For example, there are numerous Norths, and the differences often depend on mobility and the level of access to roads [45]. Perhaps even more important is whether the city is located in Russia, Scandinavia, or North America. The differences among these regions are profound in terms of histories, demographics, and governance.

\section{Origins of ISO 37120}

The development of urban sustainability indicators involves science, judgment, and the contributions of many parties, and requires further study [20]. Understanding ISO 37120's origins is important, because the decision to measure something implies a certain set of values around the specific metrics used [46]. Gathering the data to measure city performance is expensive. Once an indicator is defined, it is hard to make changes, in part for fear of reducing the comparability of the metrics over time [47]. Who is at the table and who is not also matters in defining what values inform the standard and what topics it will actually measure [48,49].

The development of ISO 37120 closely follows the professional history of Patricia McCarney, an entrepreneurial professor of political science and the director of the Global Cities Institute at the University of Toronto. Her online biography notes that "she was integral to the development of ISO 37120" (https://www.dataforcities.org/patricia-mccarney, accessed 13 February 2020) and continues to play a leading role in its development and implementation. Dr. McCarney drove the process leading to the creation of ISO 37120, drawing on her experiences in the World Bank and other organizations. Her groundwork made it relatively easy to win certification of the standard by the International Organization for Standardization. Currently, she serves as President and CEO of the World Council on City Data (WCCD), an organization working to build a standardized database for cities worldwide in line with ISO 37120. (https://www.dataforcities.org/patricia-mccarney, accessed 13 February 2020).

The origins of ISO 37120 lie in the Global City Indicators Facility (GCIF). McCarney established the GCIF in 2008 at the University of Toronto in partnership with the World Bank to study nine pilot cities: São Paulo, Porto Alegre, Belo Horizonte, Bogota, Cali, Montreal, Vancouver, Toronto, and King County (Seattle) [50], supported with funding from the Government of Japan [51]. Additional funding in 2013 came from the government of Ontario and a number of international agencies and corporate partners [52]. 
Within the International Organization for Standardization (ISO), the process to produce and publish ISO 37120 required 6 international meetings, 5 drafts, and 300 comments [53]. It took only two years to create ISO 37120, "since the indicators were already well tested and reported on by GCIF member cities" [50], which had selected indicators that addressed city priorities, information needs, and challenges [52]. The indicators were designed to be "meaningful to cities across the globe regardless of geography, culture, affluence, size, or political structure" [52]. The process for creating the ISO 37120 also differed from that used for other international standards in that most indicators were tested and reported on by GCIF cities before developing the international standard, rather than first developing and testing the standard within the ISO [50].

The initial standard was published on 15 May 2014, and related data was collected for Amman, Jordan; Barcelona, Spain; Bogotá, Colombia; Boston, USA; Buenos Aires, Argentina; Dubai, UAE; Guadalajara, Mexico; Haiphong, Vietnam; Helsinki, Finland; Johannesburg, South Africa; London, UK; Makati, Philippines; Makkah, Saudi Arabia; Melbourne, Australia; Minna, Nigeria; Rotterdam, the Netherlands; São Paulo, Brazil; Shanghai, China; and Toronto, Canada [14]. Four years later, the ISO issued a revised version. The 2014 version of ISO 37120 had 139 indicators (46 core, 54 supporting, and 39 profile). The revised 2018 version included 128 indicators ( 45 core, 59 supporting, and 24 profile) (see Table S1, provided as Supplementary Materials). The compilers deleted 20 core and supporting indicators and added 24 new ones, while consolidating the profile indicators. The added indicators focused on culture, urban agriculture and food, and on housing vacancy rates and living space. (https://www.iso.org/news/ref2305.html, accessed 13 February 2020). The WCCD hosts a website that publicizes the data provided by cities so far. (https://www.dataforcities.org/, accessed 16 April 2020).

\section{An Analysis of ISO 37120}

While ISO 37120 provides a comprehensive overview of city performance, it lacks a strong theoretical basis. The ISO indicator list covers 19 subject areas (see Table 2), and includes all the usual topics included in assessing urban sustainability, from economics to waste water treatment $[20,54,55]$. However, it does not provide an overall rationale for what actually makes one city more sustainable than another.

Although ISO 37120 explicitly claims to apply to all cities [53,56], it does not specifically judge cities by setting benchmarks that represent good or poor performance. Instead, by promoting voluntary standards and voluntarily supplied participation [57], the authors of ISO 37120 argue that cities will achieve a number of benefits from collecting the indicator data, such as more effective governance and service delivery, and informed decision making [58].

An explicit theory regarding what determines abstract concepts like urban sustainability would provide guidance in selecting appropriate indicators and avoid the risk of letting the statistical results define the outcome [47]. The ISO does not explicitly state its theoretical foundations; however, several hypotheses about the underlying theory can be inferred from the composition of the indicators included in the standard, and the designation of those included as "core" vs. "supporting" indicators. A first hypothesis is that all of the 19 categories are equally important, because all indicators are equally weighted. ISO 37120 does not rank cities based on their index outcomes, it simply asks cities and researchers to collect a set of data that they can use to benchmark themselves against other cities. There is no declaration that a field like energy is more important than housing or governance or some other aspect of urban life. However, as Table 2 shows, there are more core indicators for some topics: Energy, safety, and solid waste have five core indicators each, while recreation and telecommunications have none. 
Table 2. ISO 37120 core, supporting, and profile indicators.

\begin{tabular}{cccc}
\hline Theme & Core Indicators & Supporting Indicators & Profile Indicators \\
\hline Economics & 1 & 7 & 3 \\
Education & 4 & 2 & 0 \\
Energy & 5 & 2 & 2 \\
Environment and climate change & 3 & 6 & 0 \\
Finance & 2 & 2 & 2 \\
Governance & 1 & 3 & 0 \\
Health & 4 & 2 & 0 \\
Housing & 2 & 2 & 6 \\
Population and social conditions & 1 & 2 & 0 \\
Recreation & 0 & 2 & 0 \\
Safety & 5 & 5 & 0 \\
Solid Waste & 5 & 5 & 0 \\
Sport and Culture & 1 & 2 & 0 \\
Telecommunications & 0 & 2 & 2 \\
Transportation & 2 & 5 & 0 \\
Urban Planning & 1 & 3 & 3 \\
Waste water & 1 & 3 & 0 \\
Water & 3 & 1 & 0 \\
Total & 4 & 3 & 24 \\
\hline
\end{tabular}

Source: Table S1.

A second hypothesis implicit in ISO 37120 is that gender equality is considered an important criterion for sustainability. The education component of the standard includes an indicator measuring the percentage of the female school-aged population enrolled in schools. In the area of governance, the percentage of women among the total elected city officials is the only core indicator. Other studies of urban sustainability have focused on the importance of different factors, such as "the level of resources, staffing, funding, technical expertise, community support and leadership for sustainability efforts" as being crucial for sustainability policy making [59]. This focus on gender instead of other factors may skew results for Arctic cities, many of which have historically had high male sex ratios resulting from the composition of jobs in the resource extraction sector and higher female out-migration from the region, although the imbalance has been declining [9].

A third implicit hypothesis is that a relatively large number of indicators is needed to measure a city's level of sustainability. In each of its specific areas, ISO 37120 often includes a number of core, supporting, and profile indicators. For the economy section, there is one core, seven supporting, and three profile indicators (Table 2). Critics of existing indicator systems often claim that they have too many indicators, which makes them unwieldy to implement in practice [60]. Gathering the data required to complete all of the ISO 37120 requirements is a big job for any city staff or research team.

\section{ISO 37120 and Other Efforts to Measure Urban Sustainability}

There are few available studies of ISO 37120, but a large and rapidly growing literature on urban sustainability indicators reveals how ISO 37120 fits with other efforts to measure urban sustainability [21]. Other indicator sets have a more value-oriented focus. For example, the Ecocity Framework measures cities at 8 different levels from "unhealthy" to "Gaia" across 18 standards in four categories: Urban design, bio-geophysical conditions, socio-cultural features, and ecological imperatives.( https://ecocitystandards.org/framework/, accessed 16 February 2020). Rather than just provide a way of measuring cities in relation to each other, Ecocity Builders, the group that supports the Ecocity Framework, has an explicitly stated mission "to reshape and restructure cities to address global environmental challenges."(https:/ecocitystandards.org/ecocity-builders/, accessed 16 February 2020). In concrete terms, this translates to indicators with set benchmarks. For example, in the "environmentally friendly transport" category, a city can reach Ecocity Level 1 if $86 \%$ of trips are taken by walking, cycling, transit, and freight deliveries. 
The European Reference Frameworks for Sustainable Cities (RFSC) contains 30 objectives in 5 dimensions. (http://rfsc.eu/european-framework/, accessed 16 February 2020) The initiative is run by the French Ministry in charge of housing and urban development, the Council of European Municipalities and Regions, and CEREMA, a public body in support of national and local authorities in the field of sustainable development, and supports the Leipzig charter, which all EU members signed in 2007. Rather than providing quantitative benchmarks, the RFSC outlines general objectives that cities should strive for, such as "develop sustainable urban planning and land use."

The Circles of Sustainability approach, which was developed by Paul James, Director of the United Nations Global Compact Cities Program, focuses on four domains-ecology, economics, politics, and culture [61]. Using a simple, circular graphic to display indicators within these domains, the method seeks to get away from more complicated approaches, while demonstrating the interactions among the various domains. Like the EcoBuilders, Circles of Sustainability explicitly seeks to engage with the world and improve it.

Finally, a growing literature on smart cities and resilient cities suggests that smart and/or resilient features could replace sustainability as key urban metrics [23]. The ISO correctly sees smartness and resilience as complementary to sustainability, and has developed a related set of indicators to measure levels of smartness (ISO 37122) and resilience (ISO 37123).

\section{Does ISO 37120 Measure Sustainability?}

Researchers have proposed various ways to evaluate a set of indicators such as those included in the international standard [62,63]. Huovila et al. classified the ISO 37120 indicators by whether they measure input, process, output, outcome, or impact [21]. They categorized $6 \%$ of the ISO 37120 indicators as input, $0 \%$ process, $25 \%$ output, $22 \%$ outcome, and $47 \%$ impact measures. They concluded that the ISO 37120 was best suited for reporting immediate implementation of policy measures to support sustainability. Their findings suggested that only about half of the core and supporting indicators, those that focused on impact, addressed long-term sustainability.

Another approach would be to examine the extent that the ISO 37120 indicators met the sustainability requirements of being future oriented [64], comprehensive, and defined on the basis of community input. One way to assess future orientation would be to classify indicators by whether they measured outcomes, capacity, or investments. Outcome indicators simply measure the current status, but do not necessarily inform us about the likelihood that current conditions can be maintained over the long term. In contrast, capacity and investment indicators measure the ability and efforts of the city to address longer-term issues. Of the 106 core and supporting indicators, 36\% (38) measure capacity, 8\% (9) represent investments, and 56\% (59) outputs (see Table S2, provided as Supplementary Materials). These findings are similar to the results of the Huovila et al. survey, and suggest that fewer than half of the ISO 37120 indicators actually measure sustainability issues.

In terms of topics covered, the standard seems comprehensive. However, within each of the areas discussed, there is room for more effective choices in indicators. The economics area lacks an indicator assessing the extent to which a city's economy depends on regional non-renewable fossil fuel extraction or mining, which in the Arctic often underpin the city economy, as described above.

The extent to which ISO 37120 meets the standard of being community defined is difficult to measure. Some cities had a role in identifying the indicators that made up the GCIF. However, were these cities a representative sample of all cities - no arctic cities were included-and who exactly from these cities played a role in selecting the indicators? Most Arctic cities are smaller in size and have limited capacity to task professional staff to participate in such a process. The ISO stresses the public input aspect of its work, but its meetings take place in cities around the world, making it hard for most people to attend, and most comments likely come from the organizations and experts involved in drafting the standard. For Arctic cities, ISO 37120 would be a wholly exogenous set of criteria. It would not meet the four criteria of knowledge co-production as defined in Nature Sustainability [65]. These are: Context-based (situating the process in a particular context, place, or issue); pluralistic (explicitly 
recognizing the multiple ways of knowing and doing); goal-oriented (articulating clearly defined, shared, and meaningful goals that are related to the challenge at hand); and interactive (allowing for ongoing learning among actors, active engagement, and frequent interactions). ISO 37120 does not set goals that could be used to steer governance [66]. Most importantly for knowledge co-production, the standard is not situated in a specific place, but rather provides a way of looking at all cities and comparing them [67]. Finally, the ISO indicators have nothing to say about implementation. The various measures do not assess the planning process or steps that a city might take to implement measures to increase sustainability or the extent to which a city "takes sustainability seriously [19]".

\section{How Well Does ISO 37120 Work to Measure Urban Sustainability in the Arctic?}

Arctic cities, much like the rest of the cities in the world, seek to provide a variety of services to their residents and people living in the surrounding communities. All of the 19 categories of indicators (see Table 2) apply to northern cities in much the same ways that they would apply elsewhere.

In areas where the Arctic cities differ from other cities, ISO 37120 does not always provide a useful metric to make sense of the differences. First, remoteness is a distinguishing feature of Arctic cities. ISO 37120 has one indicator that examines this issue-the number of commercial air destinations connecting each city. This indicator does a good job of highlighting the small number of destinations linking Arctic cities, and it makes clear the exceptional nature of Anchorage and Reykjavik, which have established themselves as transportation hubs between Asia and Europe, and North America and Europe, respectively (Figure 3). However, there is a no measure of the road, railroad, or sea or river port connections between cities. Nor are there metrics gauging the distances to large urban centers for land and sea connections that do exist. Such measures would assess the potential role cities play in the international distribution of goods, and how easily they are provisioned. Beyond a simple focus on transportation logistics, measuring such connections would provide information on food security, since a larger number of connections would indicate a lower vulnerability for disruption of the city's supply of imported foods.

Second, ISO 37120 does not account for climate change in a dynamic sense. This finding is ironic, since the ISO 37120 authors clearly had climate change in mind when preparing the standard [68]. While there is an indicator for greenhouse gas emissions that measures the city's contribution to global climate change, there is no indicator to assess how climate change is affecting a city and how that city is responding. This is an important shortcoming, given that the Arctic region is warming much faster than the earth as a whole [69]. For example, a city might record decreasing total energy use per capita, which could either mean that the city is becoming more sustainable, or that the temperature is increasing and there is less need for space heating. Understanding the message of the indicators is often difficult, since they could be describing many different causal relationships [70]. Additionally, there are no measures of city preparations to address hazards related to a changing climate, including infrastructure engineering for permafrost thawing, coastal erosion, various types of flooding, and wildfire hazards. Some of the consequences of these events, such as increased air pollution from wildfires, would be picked up in the pollution measures, but this data would have to be interpreted in the context in which it is collected.

Third, Arctic city economies are closely tied to resource production in their immediate vicinity, whether oil and gas in the energy sector or mining. In this sense, outcome indicators ostensibly measuring the strength of the economy may be misleading because Arctic cities are more susceptible than most to swings of the boom-bust economy. Other factors that are important for Arctic city production efforts are relations with the local Indigenous population and the vagaries of constantly shifting geopolitical interests. Arctic cities depend much less on the innovation generated by the concentration of people and financial resources that is the main economic driver for most cities [71]. While scholars like Andrey Petrov have demonstrated the extent of creative capital in northern cities, northern urban areas clearly have fewer resources than their southern counterparts [72,73]. 


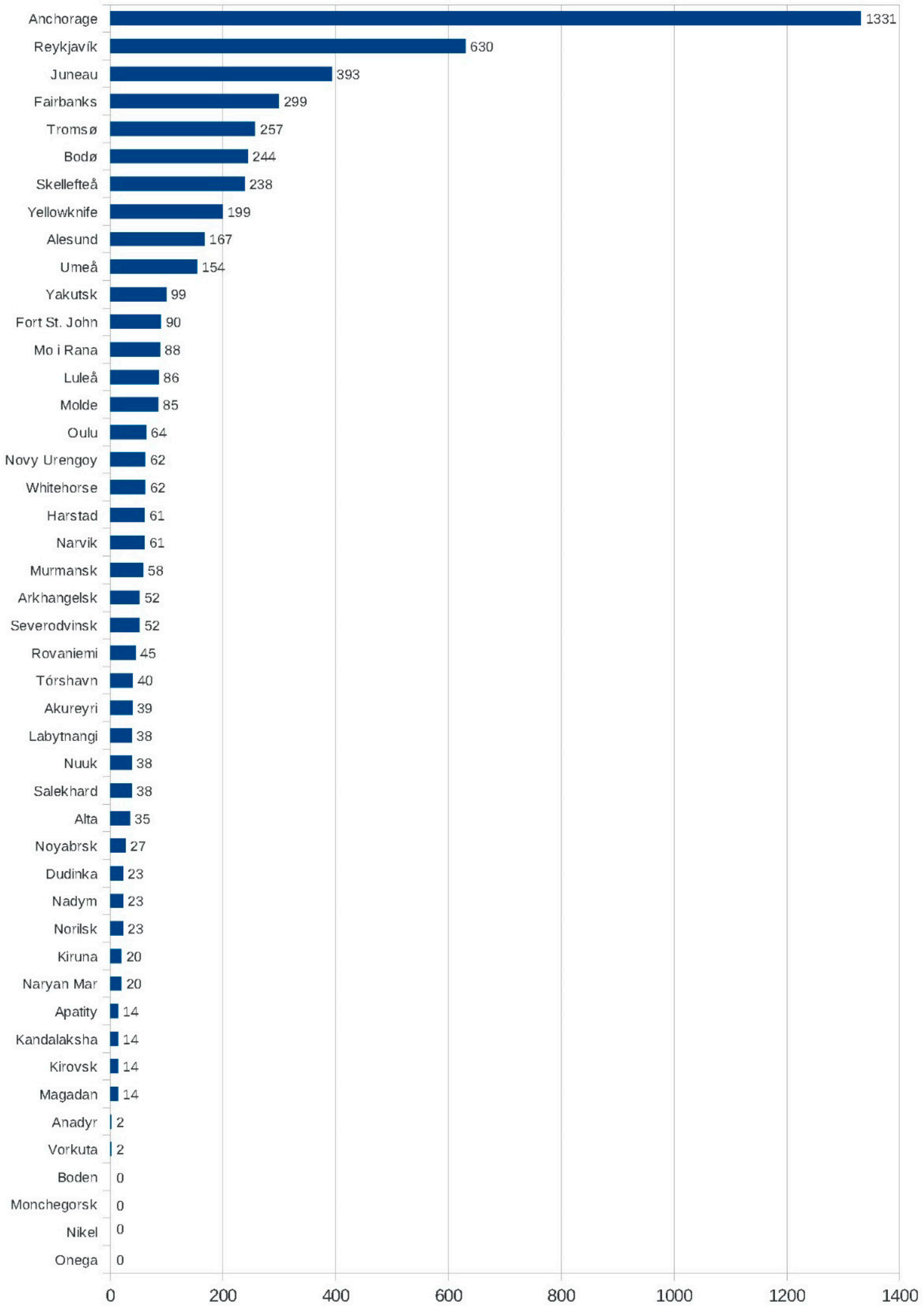

Figure 3. Commercial air connectivity of Arctic cities. (Source: ISO 37120 and http://flightradar24.com.). 


\section{Conclusions}

This article argues that although Arctic cities confront many of the same challenges as cities worldwide, they also face challenges associated with their unique geography, climate, economies, and histories. The ISO 37120 standard's comprehensive set of indicators work to benchmark Arctic urban sustainability in terms of the universal attributes of cities, but does not address the areas where they are unique in terms of remoteness, extreme climate, and economic vulnerability. Although detailed and specific, the technical complexity and large data requirements of ISO 37120 likely raise an obstacle to its widespread use in the Arctic, where cities are typically smaller and lack large professional staffs to compile the figures. At the same time, the ISO does not address important northern sustainability issues related to climate change, economic dependence on non-renewable resource extraction, and vulnerability to changing national geopolitical objectives. To be more responsive to these issues, the indicator set should focus more on measuring capacity and investments to reduce economic and social vulnerability, with less emphasis on current outcomes.

Given the proliferation of ways to measure urban sustainability, it is certainly easy to criticize ISO 37120 and other existing metrics. For example, Gómez-Álvarez et al. describe ISO 37120 as a good example of a third generation set of indicators and call for a fourth generation that would provide "a broader, people-centered approach", which would stimulate urban governance [74]. While we do not reject the use of indicators as fundamentally wrong-headed, as some have [75], we see them rather as the beginning of a conversation, a way to hold local governments accountable, and a useful component of a multi-method urban analysis [13]. ISO 37120 could be improved by more clearly articulating a theory of sustainability that would define what factors are crucial in making one city more sustainable than another. Doing so would make the assumptions underlying the choice of indicators more explicit.

To work more effectively in the Arctic, our content analysis of ISO 37120 in the light of Arctic urban conditions suggests that it should also include indicators that emphasize:

- Reliance on non-renewable resource production in the surrounding region as a central component supporting the city's economy,

- connections between a city and its broader regional ecosystem,

- relationships with and status of local Indigenous populations, and

- severity of climate vulnerability concerns such as permafrost thaw and coastal erosion, and the city's efforts to address these vulnerabilities.

Additionally, the standard should include more measures of the efforts that the city leadership is taking to increase the level of the city's sustainability overall [76].

Supplementary Materials: The following are available online at http://www.mdpi.com/2071-1050/12/9/3708/s1, Table S1: ISO 37120 Indicators, Types, Functions, and Relevance to Arctic Cities, Table S2: Summary of ISO 37120 Indicator Types, Functions, and Relevance to Arctic Cities.

Author Contributions: Conceptualization, M.B. and R.W.O.; methodology, M.B. and R.W.O.; data curation, M.B. and R.W.O.; writing-original draft preparation, M.B. and R.W.O.; writing-review and editing, M.B. and R.W.O.; project administration, M.B. and R.W.O.; funding acquisition, M.B. and R.W.O. All authors have read and agreed to the published version of the manuscript.

Funding: This research was funded by the National Science Foundation, grant number 1545913.

Acknowledgments: The authors are grateful to Jennifer Duever and Emily Zhang for help with the figures and maps.

Conflicts of Interest: The authors declare no conflict of interest.

\section{References}

1. Bogoyavlenskiy, D.; Siggner, A. Arctic Demography. In Arctic Human Development Report; Einarsson, N., Larsen, J.N., Nilsson, A., Young, O.R., Eds.; Stefansson Arctic Institute: Akureyri, Iceland, 2004; pp. $27-41$.

2. Heleniak, T. Arctic Populations and Migration. In Arctic Human Development Report; Einarsson, N., Larsen, J.N., Nilsson, A., Young, O.R., Eds.; Stefansson Arctic Institute: Akureyri, Iceland, 2013; pp. 53-104. 
3. Rasmussen, R.O. Megatrends; Danish Ministry of Foreign Affairs in collaboration with the Nordic Council of Ministers: Copenhagen, Denmark, 2011.

4. Dybbroe, S.; Dahl, J.; Müller-Wille, L. Dynamics of Arctic urbanization. Acta Boreal. 2010, 27, $120-124$. [CrossRef]

5. Larsen, J.N.; Fondahl, G. (Eds.) Arctic Human Development Report: Regional Processes and Global Linkages; Nordic Council of Ministers: Copenhagen, Denmark, 2014.

6. Southcott, C. The Social Economy and Economic Development in the Canadian North: Constraints and Opportunities. In The Political Economy of Northern Regional Development; Winther, G., Ed.; Nordic Council of Ministers: Copenhagen, Denmark, 2010; pp. 73-99.

7. Pretes, M.; Robinson, M. Beyond boom and bust: A strategy for sustainable development in the North. Polar Rec. 1989, 25, 115-120. [CrossRef]

8. Petrov, A. Exploring the Arctic's "other economies": Knowledge, creativity and the new frontier. Polar J. 2016, 6, 51-68. [CrossRef]

9. Heleniak, T. The future of the Arctic populations. Polar Geogr. 2020. [CrossRef]

10. Hiremath, R.B.; Balachandra, P.; Kumar, B.; Bansode, S.S.; Murali, J. Indicator-based urban sustainability-A review. Energy Sustain. Dev. 2013, 17, 555-563. [CrossRef]

11. Lowe, M.; Whitzman, C.; Badland, H.; Davern, M.; Aye, L.; Hes, D. Planning Healthy, Liveable and Sustainable Cities: How Can Indicators Inform Policy? Urban Policy Res. 2015, 33, 131-144. [CrossRef]

12. Davis, K.E.; Kingsbury, B.; Merry, S.E. Introduction: Global Governance by Indicators. In Governance by Indicators: Global Power through Quantification and Rankings; Davis, K.E., Fisher, A., Kingsbury, B., Merry, S.E., Eds.; Oxford University Press: Oxford, UK, 2012.

13. Mair, S.; Jones, A.; Ward, J.; Christie, I.; Druckman, A.; Lyon, F. A Critical Review of the Role of Indicators in Implementing the Sustainable Development Goals. In Handbook of Sustainability Science and Research; Filho, W.L., Ed.; Springer Nature: Cham, Switzerland, 2018.

14. ISO. Sustainable Development of Communities-Indicators for City Services and Quality of Life; ISO 37120; Interational Organization for Standardization: Geneva, Switzerland, 2014.

15. ISO. Sustainable Cities and Communities_Indicators for City Services and Quality of Life; ISO 37120; International Organization for Standardization: Geneva, Switzerland, 2018.

16. Hardoy, J.E.; Mitlin, D.; Satterthwaite, D. Sustainable cities. Environ. Urban. 1992, 4, 3-8.

17. Gardner, G. Imagining a Sustainable City. In State of the World: Can a City Be Sustainable? Worldwatch Institute, Ed.; Island Press: Washington, DC, USA, 2016; pp. 3-9.

18. Rodriguez-Pereyra, G. Nominalism in Metaphysics. In Stanford Encyclopedia of Philosophy; Zalta, E.N., Ed.; Stanford Center for the Study of Language and Information: Stanford, CA, USA, 2015.

19. Portney, K.E. Taking Sustainable Cities Seriously: Economic Development, the Environment, and Quality of Life in American Cities; The MIT Press: Cambridge, UK, 2013.

20. National Academies of Sciences Engineering and Medicine. Pathways to Urban Sustainability: Challenges and Opportunities for the United States; The National Academies Press: Washington, DC, USA, 2016.

21. Huovila, A.; Bosch, P.; Airaksinen, M. Comparative analysis of standardized indicators for Smart sustainable cities: What indicators and standards to use and when? Cities 2019, 89, 141-153. [CrossRef]

22. Nilsson, A.E.; Larsen, J.N. Making Regional Sense of Global Sustainable Development Indicators for the Arctic. Sustainability 2020, 12, 1027. [CrossRef]

23. Raspotnik, A.; Grønning, R.; Herrmann, V. A tale of three cities: The concept of smart sustainable cities for the Arctic. Polar Geogr. 2020, 43, 64-87. [CrossRef]

24. Streletskiy, D.A.; Suter, L.J.; Shiklomanov, N.I.; Porfiriev, B.N.; Eliseev, D.O. Assessment of climate change impacts on buildings, structures and infrastructure in the Russian regions on permafrost. Environ. Res. Lett. 2019, 14. [CrossRef]

25. Serreze, M.C.; Barrett, A.P.; Stroeve, J.C.; Kindig, D.N.; Holland, M.M. The emergence of surface-based Arctic amplification. Cryosphere 2009, 3, 11-19. [CrossRef]

26. Huskey, L.; Maaenpaa, I.; Pelyasov, A. Economic Systems. In Arctic Human Development Report (AHDR-II). Regional Processes and Global Linkages; Larsen, J.N., Fondahl, G., Eds.; Nordic Council of Ministers: Copenhagen, Denmark, 2014; pp. 151-184.

27. Mankova, P. Making Sense of the Remote Areas: Films and Stories from a Tundra Village. Sibirica 2018, 17, 60-84. [CrossRef] 
28. Pretes, M. Postmodern tourism: The Santa Claus Industry. Ann. Tour. Res. 1995, 22, 1-15. [CrossRef]

29. Huskey, L. Challenges to Economic Development Dimensions of "Remoteness" in the North. Polar Geogr. 2005, 29, 119-125. [CrossRef]

30. Huskey, L.; Morehouse, T.A. Development in remote regions: What do we know? Arctic 1992, 45, $128-137$. [CrossRef]

31. Harsem, Ø.; Eide, A.; Heen, K. Factors influencing future oil and gas prospects in the Arctic. Energy Policy 2011, 39, 8037-8045. [CrossRef]

32. Henderson, J.V. Cities and Development. J. Reg. Sci. 2010, 50, 515-540. [CrossRef]

33. Lucas, R.E. On the Mechanics of Economic Development. J. Monet. Econ. 1988, 12, 3-42. [CrossRef]

34. Black, D.; Henderson, J.V. A Theory of Urban Growth. J. Political Econ. 1999, 107, 252-284. [CrossRef]

35. Duranton, G. Cities: Engines of Growth and Prosperity for Developing Countries? The International Bank for Reconstruction and Development/The World Bank: Washington, DC, USA, 2008.

36. Heleniak, T. Population, Health, and Migration. In Understanding Contemporary Russia, 2nd ed.; Bressler, M., Ed.; Lynne Rienner Publishers: Boulder, CO, USA, 2013.

37. Goldsmith, O.S.; Huskey, T.L.; Berman, M.D. An interactive multi-regional model of a frontier economy: Anchorage and the State of Alaska. Reg. Sci. Perspect. 1987, 17, 55-76.

38. Nyseth, T. Arctic Urbanization: Modernity Without Cities. In Arctic Environmental Modernities; Körber, L.-A., MacKenzie, S., Stenport, A.W., Eds.; Springer: Cham, Switzerland, 2017; pp. 59-70.

39. Dawson, J.; Maher, P.T.; Slocombe, S.D. Climate Change, Marine Tourism, and Sustainability in the Canadian Arctic: Contributions from Systems and Complexity Approaches. Tour. Mar. Environ. 2007, 4, 69-83. [CrossRef]

40. Dawson, J.; Stewart, E.J.; Johnston, M.E.; Lemieux, C.J. Identifying and evaluating adaptation strategies for cruise tourism in Arctic Canada. J. Sustain. Tour. 2016, 24, 1425-1441. [CrossRef]

41. Palma, D.; Varnajot, A.; Dalen, K.; Basaran, I.K.; Brunette, C.; Bystrowska, M.; Korablina, A.D.; Nowicki, R.C.; Ronge, T.A. Cruising the marginal ice zone: Climate change and Arctic tourism. Polar Geogr. 2019, 42, 215-235. [CrossRef]

42. Laruelle, M. The three waves of Arctic urbanisation. Drivers, evolutions, prospects. Polar Rec. 2019, 55, 1-12. [CrossRef]

43. Sugden, D. Arctic and Antarctic: A Modern Geographical Synthesis; Basil Blackwell: Oxford, UK, 1982.

44. Zamyatina, N.; Goncharov, R. Arctic urbanization: Resilience in a condition of permanent instability-The case of Russian Arctic cities. In Resilience and Urban Disasters; Nijkamp, K., Ed.; Edward Elgar Publishing: Cheltenham, UK, 2019; pp. 136-153.

45. Sheppard, L.; White, M. Many Norths: Spatial Practice in a Polar Territory; Actar Publishers: New York, NY, USA, 2017.

46. Muller, J.Z. The Tyranny of Metrics; Princeton University Press: Princeton, NJ, USA, 2018.

47. Engel, L.C.; Rutkowski, D.; Thompson, G. Toward an international measure of global competence? A critical look at the PISA 2018 framework. Glob. Soc. Educ. 2019, 17, 117-131. [CrossRef]

48. Stone, D. The 2017 James Madison Award Lecture: The Ethics of Counting. PS Political Sci. Politics 2018, 51, 7-15. [CrossRef]

49. Auld, E.; Morris, P. The OECD's Assessment of Global Competence: Measuring and Making Global Elites. In The Machinery of School Internationalisation in Action: Beyond the Established Boundaries; Engel, L., Maxwell, C., Yemini, M., Eds.; Routledge: London, UK, 2019; pp. 17-35.

50. McCarney, P. The evolution of global city indicators and ISO37120: The first international standard on city indicators. Stat. J. Iaos 2015, 31, 103-110. [CrossRef]

51. Hoornweg, D. The Evolution of City Indicators: Challenges and Progress. In Cities and Global Governance: New Sites for International Relations; Amen, M., Toly, N.J., McCarney, P.L., Segbers, K., Eds.; Routledge: London, UK, 2016.

52. Hoornweg, D.; Freire, M. Building Sustainability in an Urbanizing World; World Bank: Washington, DC, USA, 2013.

53. Hurth, V.; McCarney, P. International standards for climate-friendly cities. Nat. Clim. Chang. 2015, 5, 1025-1026. [CrossRef]

54. Cohen, S. The Sustainable City; Columbia University Press: New York, NY, USA, 2018. 
55. Keeley, M.; Benton-Short, L. Urban Sustainability in the US: Cities Take Action; Palgrave-Macmillan: Cham, Switzerland, 2019.

56. Simon, D.; Arfvidsson, H.; Anand, G.; Bazaz, A.; Fenna, G.; Foster, K.; Jain, G.; Hansson, S.; Evans, L.M.; Moodley, N.; et al. Developing and testing the Urban Sustainable Development Goal's targets and indicators-A five-city study. Environ. Urban. 2015, 28, 49-63. [CrossRef]

57. Kirton, J.J.; Trebilcock, M.J. Introduction: Hard Choices and Soft Law in Sustainable Global Governance. In Hard Choices, Soft Law: Voluntary Standards in Global Trade, Environment and Social Governance; Kirton, J.J., Trebilcock, M.J., Eds.; Routledge: London, UK, 2004/2016; pp. 3-32.

58. McCarney, P. Building high calibre city data. Econ. Dev. J. 2017, 16, 7-17.

59. Swann, W.L.; Deslatte, A. What do we know about urban sustainability? A research synthesis and nonparametric assessment. Urban Stud. 2019, 56, 1729-1747. [CrossRef]

60. James, P.; Scerri, A. Auditing Cities through Circles of Sustainability. In Cities and Global Governance: New Sites for International Relations; Amen, M., Toly, N.J., McCarney, P.L., Segbers, K., Eds.; Routledge: London, UK, 2016.

61. James, P. Urban Sustainability in Theory and Practice: Circles of Sustainability; Routledge: London, UK, 2015.

62. Breslow, S.J.; Allen, M.; Holstein, D.; Sojka, B.; Barnea, R.; Basurto, X.; Carothers, C.; Charnley, S.; Coulthard, S.; Dolšak, N.; et al. Evaluating indicators of human well-being for ecosystem-based management. Ecosyst. Health Sustain. 2017, 3, 1-18. [CrossRef]

63. Breslow, S.J.; Sojkab, B.; Barnea, R.; Basurto, X.; Carothers, C.; Charnley, S.; Coulthard, S.; Dolšak, N.; Donatuto, J.; García-Quijano, C.; et al. Conceptualizing and operationalizing human wellbeing for ecosystem assessment and management. Environ. Sci. Policy 2016. [CrossRef]

64. Wu, J.; Wu, T. Sustainability indicators and indices. In Handbook of Sustainable Management; Madu, C.N., Kuei, C., Eds.; Imperial College Press: London, UK, 2012; pp. 65-86.

65. Norström, A.V.; Cvitanovic, C.; Löf, M.F.; West, S.; Wyborn, C.; Balvanera, P.; Bednarek, A.T.; Bennett, E.M.; Biggs, R.; Bremond, A.D.; et al. Principles for knowledge co-production in sustainability research. Nat. Sustain. 2019. [CrossRef]

66. Young, O.R. Conceptualization: Goal Setting as a Strategy for Earth System Governance. In Governing through Goals: Sustainable Development Goals as Governance Innovation; Kanie, N., Biermann, F., Eds.; The MIT Press: Cambridge, MA, USA, 2017; pp. 31-51.

67. McFarlane, C. The Comparative City: Knowledge, Learning, Urbanism. Int. J. Urban Reg. Res. 2010, 34, 725-742. [CrossRef]

68. McCarney, P.L. City Indicators on Climate Change Implications for Governance. Environ. Urban. Asia 2012, 3, 1-39. [CrossRef]

69. IPCC. IPCC Special Report on the Ocean and Cryosphere in a Changing Climate; Pörtner, H.-O., Roberts, D.C., Masson-Delmotte, V., Zhai, P., Tignor, M., Poloczanska, E., Mintenbeck, K., Alegría, A., Nicolai, M., Okem, A., et al., Eds.; IPCC: Geneva, Switzerland, 2019.

70. McManus, P. Measuring Urban Sustainability: The potential and pitfalls of city rankings. Aust. Geogr. 2012, 43, 411-424. [CrossRef]

71. Glaeser, E. Triumph of the City: How Our Greatest Invention Makes Us Richer, Smarter, Greener, Healthier, and Happier; The Penguin Press: New York, NY, USA, 2011.

72. Petrov, A. Arctic's Emerging 'Other' Economies: Technology, Knowledge and Culture in the New Arctic Economy. In The Economy of the North 2015; Glomsrød, S., Duhaime, G., Aslaksen, I., Eds.; Statistics Norway: Oslo, Norway, 2017; pp. 74-77.

73. Petrov, A.N. From Sustaining Creativity to Creating Sustainability: Talent and Creative Capital for Sustainable Development in Arctic Urban Communities; Institute for European, Russian and Eurasian Studies Arctic Urban Sustainability Conference: Washinton, DC, USA, 2013.

74. Gómez-Álvarez, D.; López-Moreno, E.; Bilsky, E.; Ochoa, K.B.; Lara, E.O. Indicators for Measuring Urban Sustainability and Resilience. In Urban Planet: Knowledge toward Sustainable Cities; Elmqvist, T., Bai, X., Frantzeskaki, N., Griffith, C., Maddox, D., McPhearson, T., Parnell, S., Romero-Lankao, P., Simon, D., Watkins, M., Eds.; Cambridge University Press: Cambridge, UK, 2018; pp. 163-179. 
75. Kaika, M. 'Don't call me resilient again!': The New Urban Agenda as immunology ... or ... what happens when communities refuse to be vaccinated with 'smart cities' and indicators. Environ. Urban. 2017, 29, 89-102. [CrossRef]

76. Laruelle, M. Norilsk: Measuring Sustainability in Population Size and Well-Being. In Urban Sustainability in the Arctic: Measuring Progress in Circumpolar Cities; Orttung, R.W., Ed.; Berghahn: New York, NY, USA, 2020; pp. 74-100.

(c)

(C) 2020 by the authors. Licensee MDPI, Basel, Switzerland. This article is an open access article distributed under the terms and conditions of the Creative Commons Attribution (CC BY) license (http://creativecommons.org/licenses/by/4.0/). 